\title{
Efficient Design of a Photovoltaic Water Pumping and Treatment System
}

\author{
${ }^{1}$ Abderrahmen Ben Chaabene, ${ }^{1}$ Med Faouzi Elkaroui and ${ }^{2}$ Anis Sellami \\ ${ }^{1,2}$ Department of Electrical Engineering, Unit Research on Renewable Energies (URER), \\ High School on Technological Studies of Bizerte, BP 65-University Campus, 7035 Bizerte, Tunisia \\ ${ }_{1,2}$ High School of Sciences and Techniques, 5 Taha Hussein Street, BP.56, 1008 Tunis, Tunisia
}

Received 2012-01-18, Revised 2012-12-27; Accepted 2013-07-04

\begin{abstract}
Through the world, the exploitation of solar energies knew a strong growth these last years. It is interesting to exploit them on the place of consumption, by directly transforming into heat, or in electricity according to needs and especially in remote areas where power from utility is not available or is too costly to install. The use of photovoltaic sources in water pumping and treatment domain is one of the most important renewable energy applications. Having an arid to a semi-arid climate, Tunisia receives low quantities of rain. Consequently, the available water resources in the country are rather modest in terms of both quantity and quality. $97 \%$ of water resources in Tunisia are of brackish water, particularly in the south parts of the country. Originate from ground water resources and surface, these waters are unsuitable for drinking or irrigation, because of the high salinity and biological contagion in sensitive (perceptible) germs. The goal of this study is to direct the applied researches to the applications of coupling the photovoltaic energy, which is available in the south of the country and water domain (pumping, desalting and disinfecting). We present in this study some of pilot units coupled to photovoltaic sources and we propose a global system which gathers the water pumping, desalting and disinfecting operations. Some experimental and numerical results have been carried out to show the efficiency of the use of this system. The conception, the realization and the exploitation of this autonomous system will be the suitable solution for providing fresh water to a number of rural regions where important quantities of water are needed to either, the drinking and irrigation, in Tunisia and in the Mediterranean basin in general.
\end{abstract}

Keywords: Renewable Energy, Water Treatment, Photovoltaic Energy, Autonomous System, Biological Contagion, Coupling Between, Desalination Unit, Huge Quantities

\section{INTRODUCTION}

The water and the energy can be considered the two basic elements supporting life and the natural environment. The supply of safe water for domestic use and irrigations in desert regions remains the worry of the Saharan coast countries especially those who have remote villages and farms far away from the electric grid. The photovoltaic PV pumping and treating systems become the appropriate solution to overcome this problem especially in desert regions. There are two main advantages that help to profit from such new technology: the availability of free source of energy which is the sun and the abundance of the underground water sources. As water is customarily used and needed in large quantities, it is important to minimize consumption of and expenditure on, energy whenever possible. With this goal in mind it is not surprising to note the increased interest to the coupling of water treatment and pumping systems with photovoltaic energy. In literature many studies have talked about each system alone .but the idea of gathering all of these systems in a one autonomous

Corresponding Author: Abderrahmen Ben Chaabene, Department of Electrical Engineering, Unit Research on Renewable Energies (URER), High School on Technological Studies of Bizerte, BP 65-University Campus, 7035 Bizerte, Tunisia 
system, coupled to photovoltaic source is interesting. We will present firstly the diagrams of each one of them, we'll explain their principles then we proposed a coupling between all these pilot units.

\section{MATERIALS AND METHODS}

\subsection{The Photovoltaic Generator}

The use of PV generators makes easily the use of solar energy, free, clean and inexhaustible. For the best exploitation of this energy and a continuous product of water, we must install the recharged batteries.
The PV generator consists of an array of photovoltaic cell modules connected in series-parallel combination to provide the desired DC voltage and current.

The coupling of the battery with the PV generator is realized through a charge regulator, the equivalent electrical diagram of the total energetic system is shown in Fig. 1.

In order to exploit the maximum of the available energy, we have to work at a Maximum Power Point Tracking (MPPT) (Hussein et al., 1995).

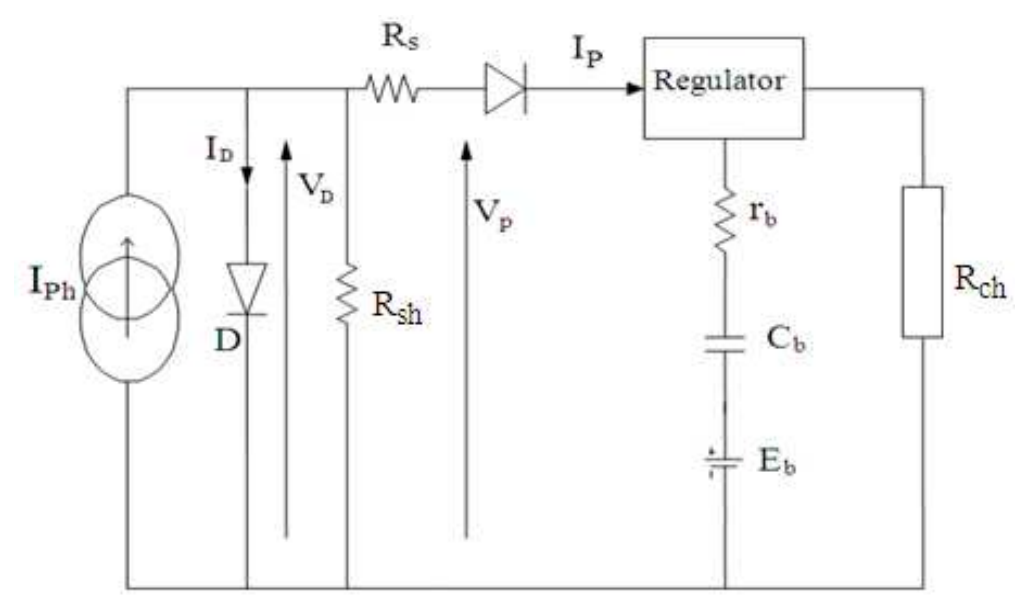

Fig. 1. The energetic system equivalent diagram

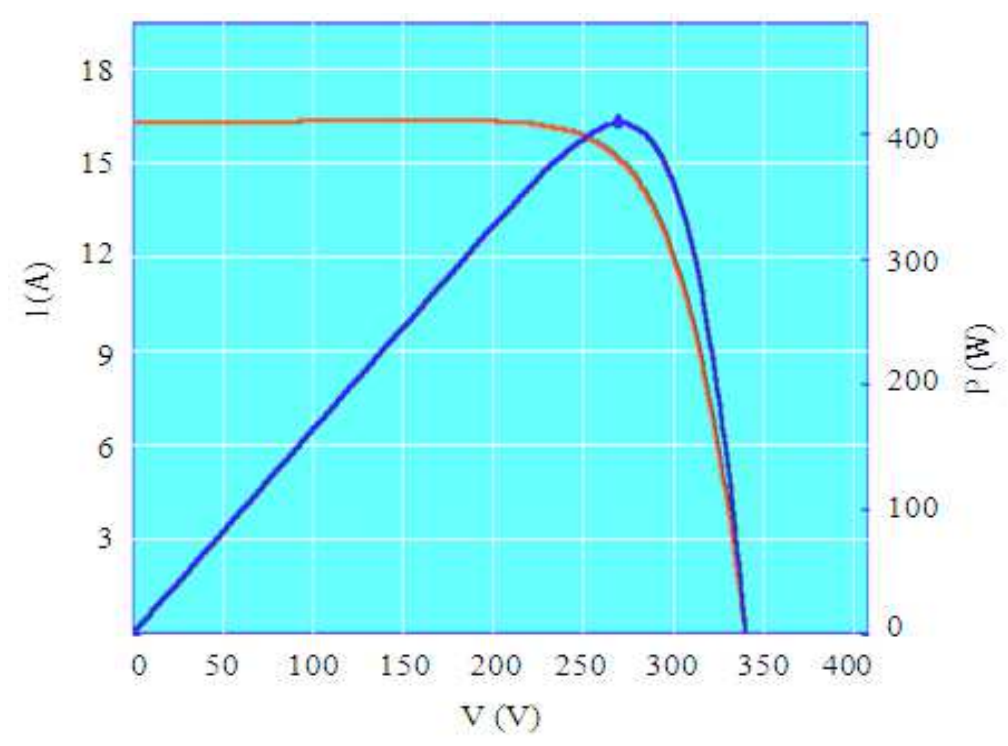

Fig. 2. Characteristic of photovoltaic panel 


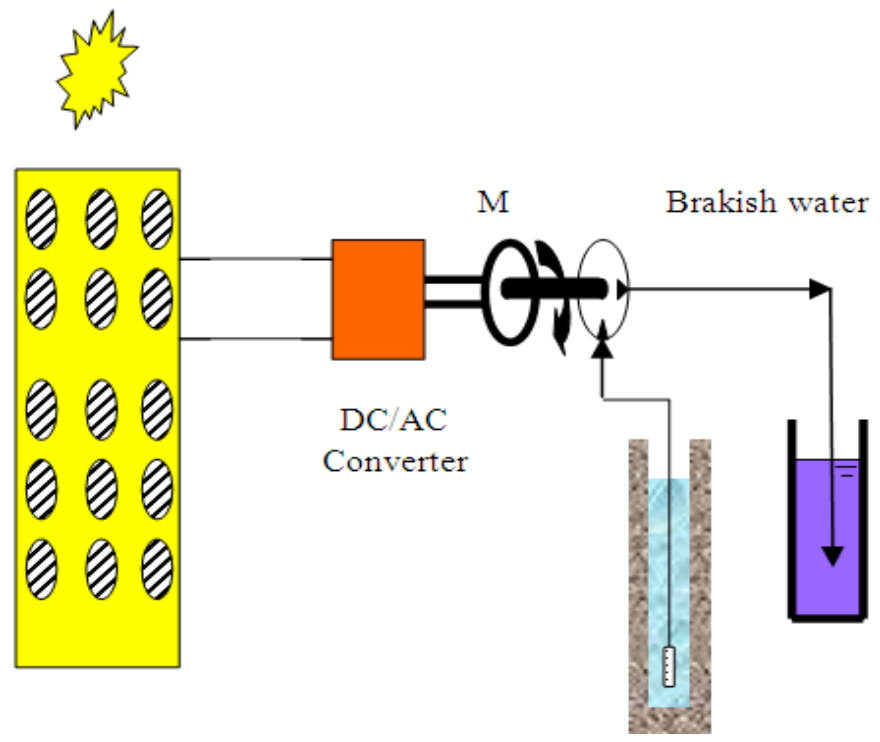

Fig. 3. Photovoltaic pumping system design

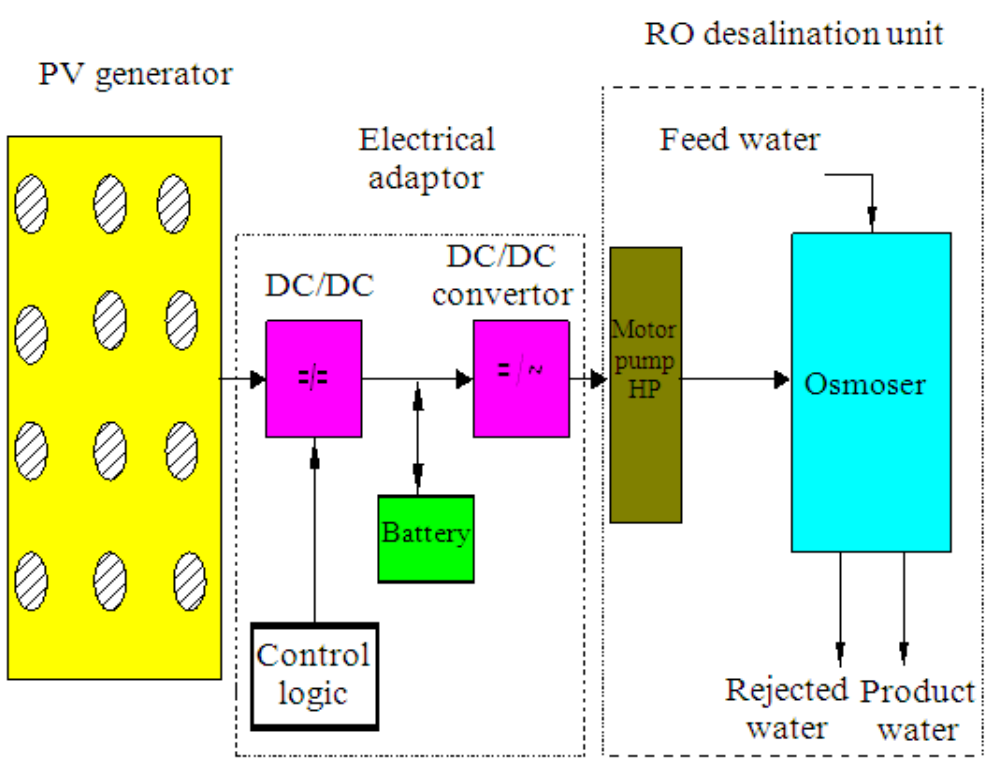

Fig. 4. The desalination system configuration

The Fig. 2 shows the I-V and P-V, characteristic. The intersection between the two caracteristic gives the Maximum Power Point. This type of tracking depends on climatic conditions.

\subsection{The PV Pumping System}

The PV pumping system consists on a $\mathrm{PV}$ generator followed by a DC/DC converter and/ or a DC/AC converter depending on the type of the Moto pump (Bourouni and
Chaibi, 2009). The pumping system, with a simple design, showed in the following Fig. 3 does not need a storage system of the electrical energy. The best solution is to stock the pumped water to be used when needed.

\subsection{The Desalination System}

The system configuration is shown in Fig. 4. It is composed by three compartments: The photovoltaic generator, the electrical adaptor and the desalination unit. 


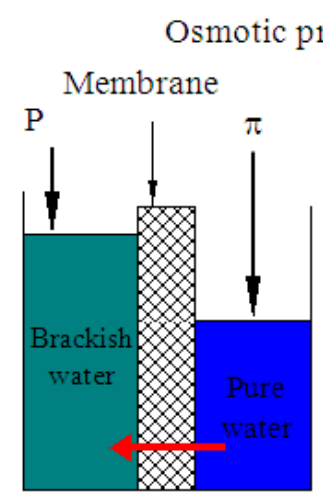

$\pi>\mathrm{P}$

Direct osmosis

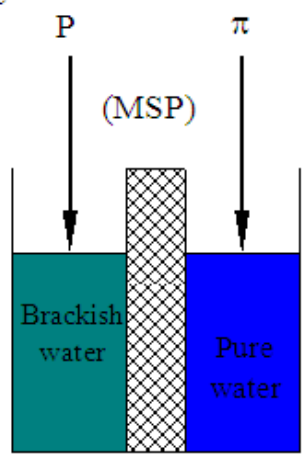

$\pi=\mathrm{P}$

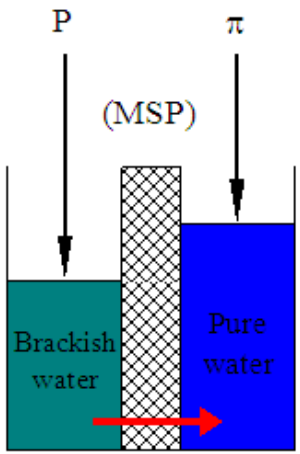

$\pi<\mathrm{P}$

Reverse osmosis

Fig. 5. Reverse osmosis principle

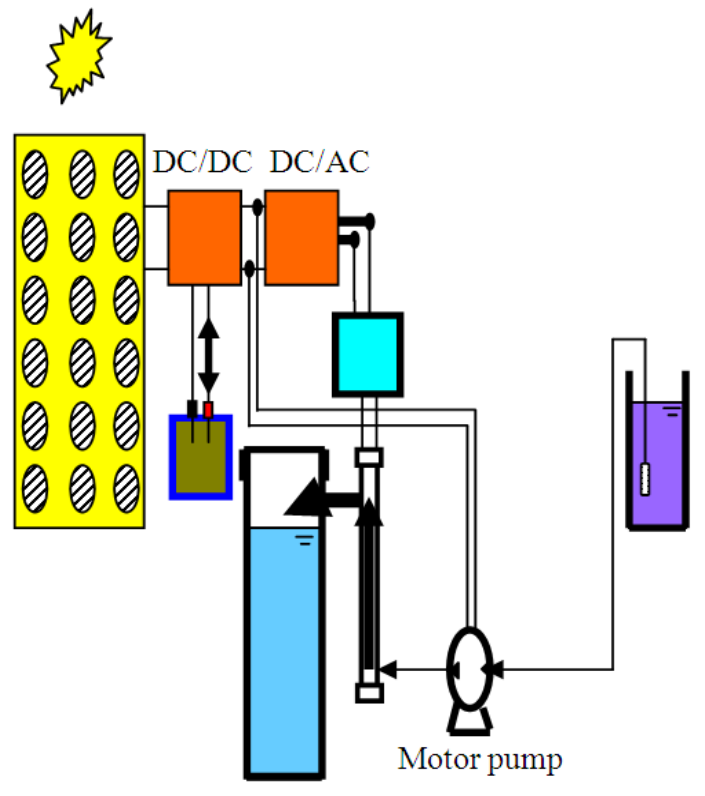

Fig. 6. Synoptic diagram of the water disinfecting system

The adaptor converts the continuous voltage delivered by the battery to an alternative voltage in order to feed the motor pump group which provides pressurized water to the membrane. The desalination unit is composed by three RO modules, each one of them is composed by a membrane which is constituted of a thin film composite modified polyamide type able to purify feed water containing up to $3,000 \mathrm{ppm}$ of total dissolved solids. These modules have a nominal capacity $1500 \mathrm{~L} / \mathrm{d}$ at 800 $\mathrm{kPa}$ (Bouguecha et al., 2005).

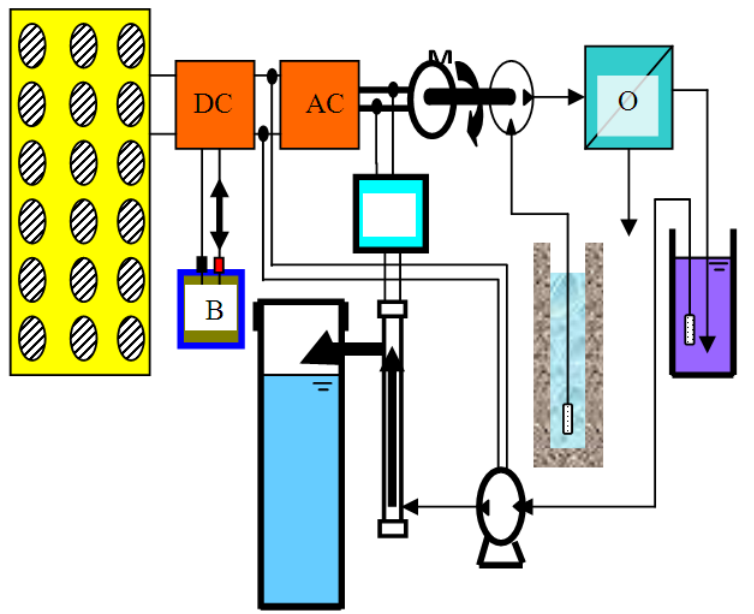

Fig. 7. Synoptic diagram of the global PDT water system

\subsection{Reverse Osmosis Principle}

When we try to separate pure water and a salt solution through a semi permeable membrane, the pure water diffuses through the membrane and dilutes the salt solution, this phenomenon is known as natural or direct osmosis. As water passes through the membrane, the pressure on the dilute side drops and the pressure of the concentrated solution rise. The osmotic flux continues until an equilibrium is reached, where the net water flux through the membrane becomes zero at equilibrium; the liquid level in the saline water will be higher than that on the water side. The amount of water passing in either direction achieved is equal to the reverse osmosis principle. 
The amount of water passing in either direction achieved is equal to the effective driving force causing the flow, called osmotic pressure noted $\Pi$ which is due to the difference between the salt concentration of both of the feed and the product water. This pressure is a strong function of the solute concentration and the temperature and depends on the type of ionic species present (Robertson et al., 1996). Applying a pressure $\mathrm{P}$ in excess of the osmotic pressure to the saline water slows down the osmotic flow and forces the water to flow from the salt solution into the water side. Therefore, the direction of flow is reversed and that is why this separation process is called reverse osmosis. The Fig. 5 shows the reverse osmosis principle (Chaabene and Sellami, 2010).

\subsection{Water Disinfecting System}

Often pumped waters present a biological contagion in sensitive (perceptible) germs, consequently the Ultraviolet (UV) irradiations is the best solution to solve this bacteriological problem of the drinking water quality (Hassen et al., 1999). The UV irradiations are produced by a gas-discharge lamp. The circulation of water to treat through the lamp provokes the infiltration of the radiations in this water and by consequent destroys pathogenic germs. Indeed an irradiation wave length of $265 \mathrm{~mm}$ induces a chemical reaction on the ARN and the ADN of the micro-organisms involving their deactivation (Parotta and Bekdash, 1998).

The UV water disinfecting unit fed by a PV source showenby Fig. 6 is constituted by:

- Two storage tank, one for the water to treat, the other is for treated water

- A reactor based on the UV lamp

- A Moto pump to circulate water between the two tanks through the lamp

- Electrochemical batteries allowing the storage

- A ballast which is an inverter followed by a transformer, able to create high frequency tension and an increase in the voltage value for a short time on the UV lamp

- The PV panels

- The Electrical adaptors

\subsection{The Pumping Desalting and Treating Water System (PDT Water System)}

The system is the combination between the three operations of pumping desalting and disinfecting system Fig. 7. The use of Moto pump with two roles: Pumping and desalination is a suitable solution to minimize the energy consumption then the integration of the treatment water system covers for any future deficit in potable water and improve the quality of distributed drinking water with a demand estimated at more than $877 \mathrm{Mm}^{3} /$ year at 2025 (Houcine et al., 1999).

\section{RESULTS}

Some experimental results are shown by the following figures.

\section{DISCUSSION}

The Fig. 8 shows that the available irradiance measured over two days test is with important quantities (more than $500 \mathrm{~W} . \mathrm{m}^{-2}$ while at least $8 \mathrm{~h}$ a day).

Figure 9 and 10 illustrate that the product water flow and salinity depend strongly with the irradiance. When these last has a very low value, the production is minimum with a bad quality (higher salinity) Product water salinity behaviour. Figure 11 shows clearly that the use of a global PDT water system minimizes the energy consumption. This is mentioned previously, as the number of motor pumps has been reduced.

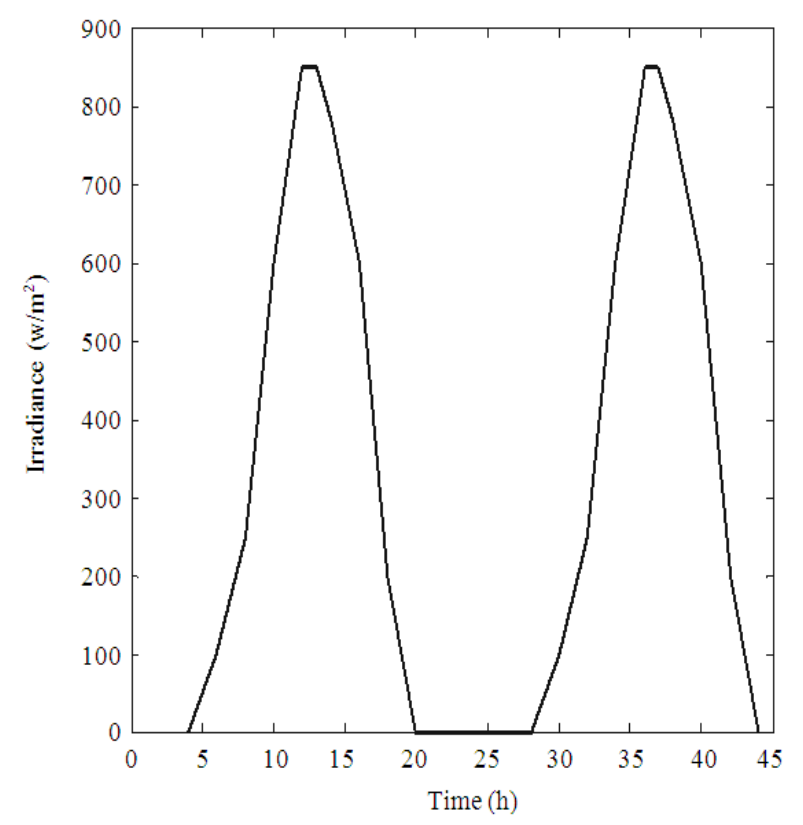

Fig. 8. Measured irradianc 
Abderrahmen Ben Chaabene et al. / American Journal of Engineering and Applied Sciences 6 (2): 226-232, 2013

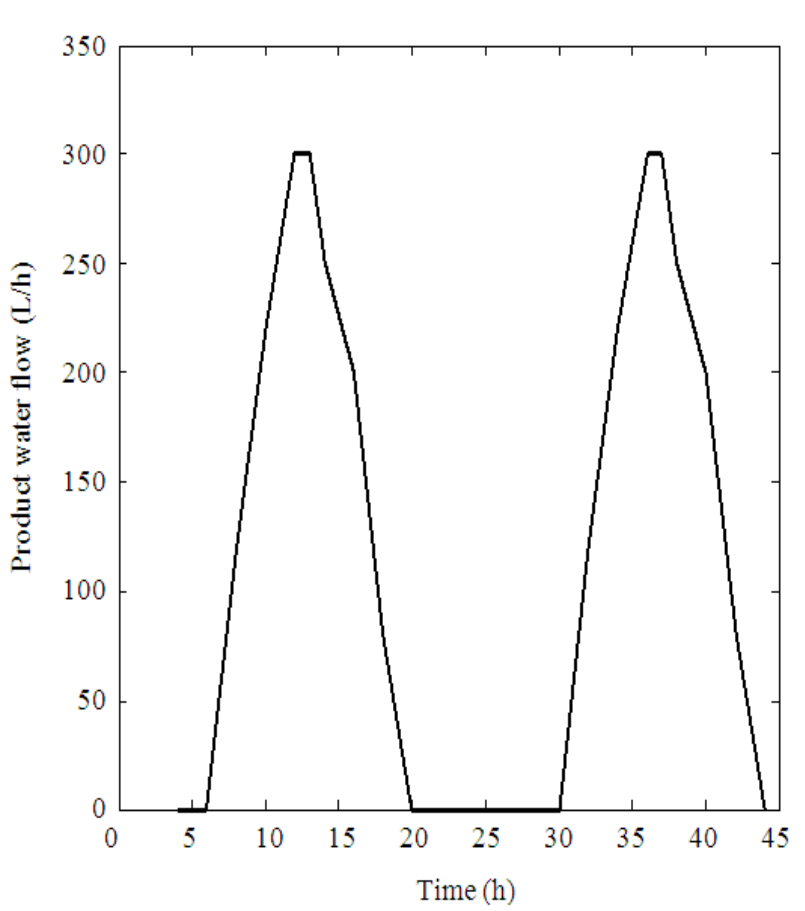

Fig. 9. Product water flow behaviour

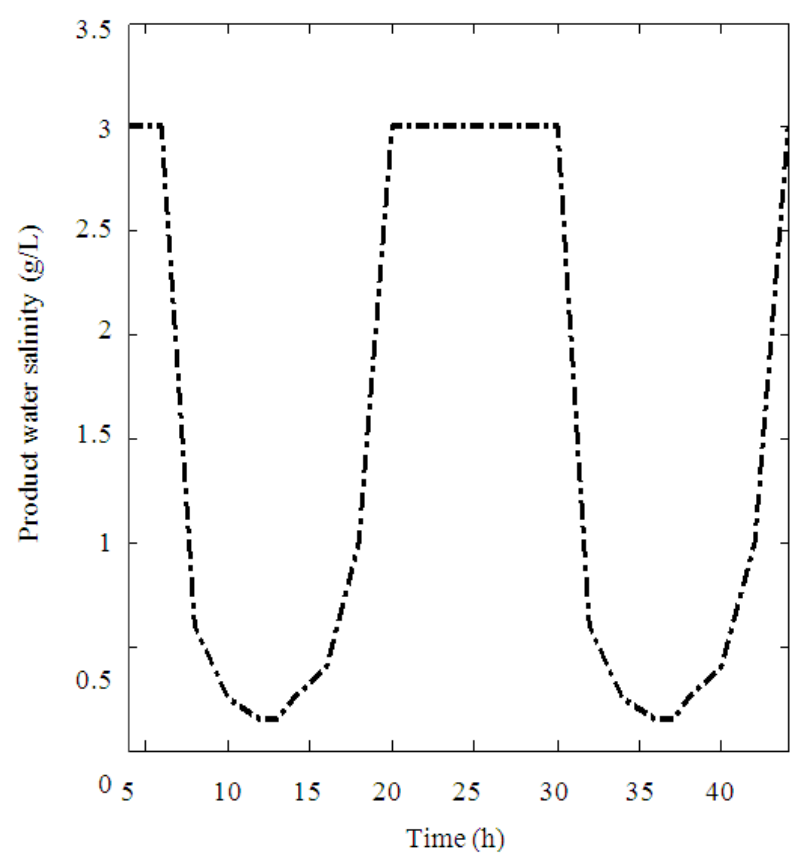

Fig. 10. Product water salinity behaviour

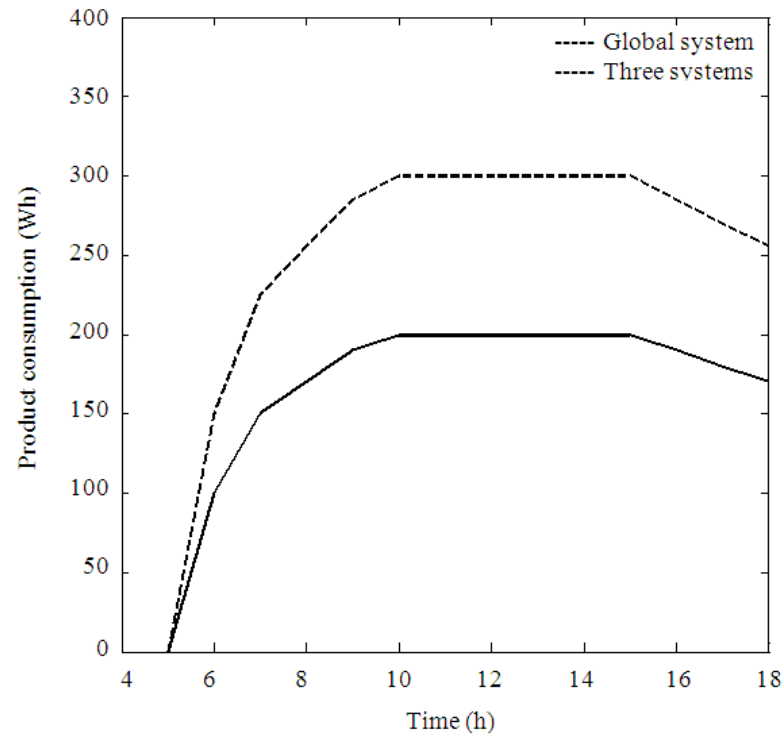

Fig. 11. Energy consumption

\section{CONCLUSION}

The prospects of the coupling between the renewable energy and the water treating systems in Tunisia show a flourishing future. The solar energy has been assessed to be available in huge quantities throughout the country and all year round.

As this form of energy is in perfect synergy with locations where the water is of a bad quality and most needed, it is well suited for powering the pumping and treatment water system. The implementation of a system which gathers the three operations coupled to photovoltaic sources will be a perfectly adequate solution to feed with potable water the majority of the small agglomerations and remote villages.

The perfection of the system and the integration of advanced control strategies will be necessary to operate the system at optimum conditions and reduce the product water cost.

\section{REFERENCES}

Bouguecha, S., B. Hamrouni and M. Dhahbi, 2005. Small scale desalination pilots powered by renewable energy sources: Case studies. J. Desalination, 183: 151-165. DOI: 10.1016/j.desal.2005.03.032

Bourouni, K. and M. Chaibi, 2009. Solar energy for application to desalination in Tunisia: Description of a demonstration project. Renew. Energy Middle East, 3: 125-149. DOI: 10.1007/978-1-4020-9892-5_8 
Chaabene, A.B. and A. Sellami, 2010. Multivariable Multivariable proportional integral controllers for multi-inputs-multi-outputs desalination system fed by a photovoltaic generator. Am. J. Eng. Applied Sci. 3: 265-269. DOI: 10.3844/ajeassp.2010.265.269 Hassen, A., M. Mahrouka, H. Ouzari, M. Cherif and J.J. Damelincourt, 1999. UV disinfection of treated wastewater in a large-scale pilot plant and inactivation of selected bacteria in a laboratory UV device. J. Bioresource Technol., 74: 141-150. DOI: 10.1016/s0960-8524(99)00179-0

Houcine, I., F. Benjemaa, M.H. Chahbani and M. Maalej, 1999. Renewable energy sources for water desalting in Tunisia. J. Desalination, 125: 123-132. DOI: 10.1016/s0011-9164(99)00130-7
Hussein, K.H., I. Muta, T. Hoshino and M. Osakada, 1995. Maximum tracking photovoltaic power an algorithm for rapidly changing atmospheric conditions. IEEE Proc. Gen. Trans. Dist., 142: 5964. DOI: 10.1049/ip-gtd:19951577

Parotta, M. J. and F. Bekdash, 1998. UV disinfection of small groundwater supplies. J. Am. Water Works, 90: 71-81.

Robertson, M.W., J.C. Watters, P.B. Desphande, J.Z. Assef and I. Alatiqui, 1996. Model based control for reverse osmosis desalination processes. Desalination, 104: 56-68. DOI: 10.1016/00119164(96)00026-4 